\title{
Prescribing of Direct Oral Anticoagulants in Atrial Fibrillation Based on Estimation of Renal Function Using Standard and Modified Cockcroft-Gault Equations: A Retrospective Analysis
}

\author{
Melissa Kucey, Jennifer Bolt, Lori Albers, Ali Bell, Nkem Iroh, and Julie Toppings
}

\section{INTRODUCTION}

A trial fibrillation affects about 350000 Canadians. ${ }^{1}$ A devastating complication of this condition is stroke or systemic embolism, the risk of which is 3 to 5 times greater among patients with atrial fibrillation than among those without the arrhythmia. As such, anticoagulation to prevent thrombotic complications is often required. ${ }^{1,2}$

For many years, warfarin has been the drug of choice for long-term anticoagulation in patients with atrial fibrillation. ${ }^{3}$ Apixaban, dabigatran, and rivaroxaban are 3 direct oral anticoagulants (DOACs) that have received approval from Health Canada for the prevention of stroke or systemic embolism in patients with atrial fibrillation, as alternatives to warfarin. According to the 2014 guidelines on atrial fibrillation of the Canadian Cardiovascular Society, most patients for whom an oral anticoagulant is indicated should receive a DOAC rather than warfarin (strong recommendation, high-quality evidence). ${ }^{2}$

It is estimated that about one-third of patients with atrial fibrillation also have chronic kidney disease, ${ }^{4}$ and rates of stroke, systemic embolism, and bleeding are higher in patients with renal insufficiency. ${ }^{5-7}$ All 3 DOACs undergo renal elimination to some extent, with about $80 \%$ of dabigatran, $35 \%$ of rivaroxaban, and $27 \%$ of apixaban excreted unchanged in the urine. ${ }^{8-10}$ In patients with declining renal function, DOACs can accumulate, and dose adjustments are recommended. Therefore, routine monitoring of serum creatinine $(\mathrm{SCr})$ and assessment of creatinine clearance $(\mathrm{CrCl})$ are recommended at least once a year for patients with stable renal function, more frequently if indicated. ${ }^{2}$
The Cockcroft-Gault (CG) equation uses SCr, age, weight, and sex to estimate $\mathrm{CrCl} .{ }^{11}$ The Canadian product monographs for $\mathrm{DOACs}^{8-10}$ recommend using the CG equation based on actual body weight (CG-ABW) when assessing renal function for the purpose of dose adjustments, as this was the equation used in the randomized controlled trials for these drugs. ${ }^{12-14}$ However, until the DOACs were introduced into practice, the modified CG equation, standardized to a 72-kg man, was the $\mathrm{CrCl}$ equation endorsed by the Regina Qu'Appelle Health Region pharmacy and therapeutics committee. The modified CG equation has been validated in a different population from the populations used in the randomized controlled trials; it increases the ease of estimating $\mathrm{CrCl}$ because the patient's actual body weight is not required. ${ }^{15}$

When determining an appropriate dosing regimen for the DOACs, accuracy in assessing renal function is imperative, because under- or over-dosing an anticoagulant has been shown to increase the risk of adverse outcomes secondary to thromboembolic or hemorrhagic complications, respectively. ${ }^{16}$ The purpose of this study was to determine whether the dose of apixaban, dabigatran, or rivaroxaban prescribed for elderly patients with atrial fibrillation was appropriate, based on estimation of renal function using the CG-ABW equation, and to assess the potential impact on dosing recommendations of using the modified CG equation.

The primary objective was to determine the percentage of patients for whom the appropriate dose of a DOAC was prescribed upon discharge from hospital, based on estimation of renal function using the CG-ABW equation. The secondary objectives were to identify the percentage agreement between 
dosing recommendations with the CG-ABW and modified CG equations and to categorize the types of physicians prescribing DOACs upon hospital discharge.

\section{METHODS}

\section{Study Design}

This study was a retrospective chart review of patients with atrial fibrillation who were discharged from 2 tertiary care teaching hospitals. Ethics approval was granted by the Regina Qu'Appelle Health Region Research Ethics Board (REB-14-133).

\section{Selection of Participants}

Patients 65 years or older with a diagnosis of atrial fibrillation who were discharged between January and August 2014 and who were taking apixaban $5 \mathrm{mg}$ or $2.5 \mathrm{mg}$ twice daily, dabigatran $150 \mathrm{mg}$ or $110 \mathrm{mg}$ twice daily, or rivaroxaban $20 \mathrm{mg}$ or $15 \mathrm{mg}$ once daily while in hospital were eligible for inclusion in the study. The age criterion specified patients 65 years or older because most patients with atrial fibrillation in this age group are likely to be receiving anticoagulation, and targeting an elderly population provided more opportunity to assess the appropriateness of dose adjustments in renal dysfunction. ${ }^{2}$ Patients were excluded if they had a current indication for anticoagulation other than atrial fibrillation, if weight or SCr was not documented in the chart, or if they were not receiving a DOAC at the time of discharge. Patients were identified using BDM Pharmacy (BDM IT Solutions, Regina, Saskatchewan), the medication management software used by pharmacy services within the health region. Of the identified patients, the majority had a prescription for dabigatran or rivaroxaban, as apixaban was added to the local hospital formulary only in March 2014 (partway through the study period). Therefore, in an attempt to achieve the desired sample size and to have an even distribution of patients across the 3 DOACs, all of the patients with a prescription for apixaban and every second patient with a prescription for dabigatran or rivaroxaban were included.

\section{Data Collection}

The following information was collected from patients' charts: age, sex, weight, drug and dose at the time of patient discharge, SCr last reported in the chart before discharge, and specialty of the discharging physician. This information was then incorporated into a web-based survey tool (FluidSurveys, Ottawa, Ontario).

For each patient, the CG-ABW and modified CG equations (Appendix 1, available at www.cjhp-online.ca/index. $\mathrm{php} / \mathrm{cjhp} /$ issue/view/117/showToc) were used to calculate the $\mathrm{CrCl}$ from the information collected. The DOAC dose at discharge was then assessed for appropriateness, using recommendations in the Canadian product monograph and based primarily on renal function as determined by each $\mathrm{CrCl}$ equation (Appendix 2, available at www.cjhp-online.ca/index. $\mathrm{php} / \mathrm{cjhp} /$ issue/view/117/showToc). Discharge doses were considered appropriate, subtherapeutic, or supratherapeutic if they matched, were lower than, or were higher than the Canadian product monograph recommendations, respectively, based on calculated renal function. In addition, the dose was deemed supratherapeutic for any patient whose $\mathrm{CrCl}$ was below $30 \mathrm{~mL} / \mathrm{min}$ and who was receiving dabigatran or rivaroxaban at discharge or for any patient whose $\mathrm{CrCl}$ was below 25 $\mathrm{mL} / \mathrm{min}$ and who was receiving apixaban at discharge. For dabigatran, both the $150 \mathrm{mg}$ and $110 \mathrm{mg}$ twice daily regimens were considered appropriate if $\mathrm{CrCl}$ was greater than or equal to $30 \mathrm{~mL} / \mathrm{min}$ and the patient was 79 years of age or younger. The criteria for comparison of dosing recommendations between the CG-ABW and modified CG equations are listed in Appendix 3 (available at www.cjhp-online.ca/index.php/ cjhp/issue/view/117/showToc).

\section{Statistical Analysis}

On the basis of evidence from one previous study, which found that about $50 \%$ of patients received the correct dosing regimen for dabigatran, ${ }^{17}$ and setting the confidence limit at $95 \%$ and assuming an acceptable error rate of 5\%, the desired sample size was determined to be 132 cases. The descriptive analysis took the form of frequency distributions for categorical data. Continuous data were examined to determine whether they were normally distributed and suitable for parametric analyses. Variables with normally distributed data are summarized using the mean and standard deviation. Variables with data that were significantly skewed (determined by examination of the Fisher skewness coefficient) are presented as medians and interquartile ranges. To evaluate agreement in terms of DOAC dosing between the 2 equations (CG-ABW and modified CG), the exact percentage agreement was determined, and the kappa statistic was used to correct for chance agreement between the 2 methods. In comparing dosing recommendations generated by the CG-ABW and modified CG equations, $\chi^{2}$ analysis was used to determine whether there was a difference in the observed proportion of matched and mismatched cases that were male or female. To determine whether there was a significant difference in patient age, weight, or SCr between matched and mismatched groups, a Mann-Whitney test was performed. $\chi^{2}$ analysis was also used to determine whether there was a difference in appropriate versus inappropriate dosing by physician specialty. All analyses were performed with SPSS Statistics for Windows software, version 22.0 (released 2013; IBM Corporation, Armonk, New York). 


\section{RESULTS}

A total of 198 patients were screened for inclusion, of whom 136 met the predefined criteria (Figure 1). Patient characteristics are presented in Table 1 . Most of the patients had a prescription for either rivaroxaban ( $n=57$ [42\%]) or dabigatran $(n=52[38 \%])$; the remainder were to receive apixaban $(n=27[20 \%])$. For one of the patients who was receiving rivaroxaban, the prescribed dosage was $15 \mathrm{mg}$ daily while in hospital, but the dosage upon discharge was $10 \mathrm{mg}$ daily.

The assessments of discharge doses in relation to recommendations in the Canadian product monographs are summarized in Table 2. Overall, on the basis of the CG-ABW equation, the prescribed dose upon discharge was appropriate for $102(75 \%)$ of the patients. For the 34 (25\%) patients whose prescribed discharge dose was inappropriate on the basis of the CG-ABW equation, the prescribed dose was subtherapeutic for 20 (15\% of the entire sample) and supratherapeutic for 14 (10\%); within the latter group, 8 patients $(6 \%$ of the entire sample) had a prescription for DOAC but should not have received this type of therapy because of renal insufficiency.

The CG-ABW and modified CG equations resulted in the same dosing recommendations for 120 of the 136 patients, providing an overall percent agreement of $88 \%$ (kappa $=0.695$, $p<0.001)$. Of the remaining 16 patients, for whom the 2 equations resulted in different dosing recommendations, the modified CG equation would have led to 6 subtherapeutic doses and 10 supratherapeutic doses (and for 5 of these latter cases, DOAC use would not be recommended because of renal insufficiency) (Table 3). Age, sex, weight, and SCr were analyzed in an attempt to identify which variables accounted for the discrepancies in dosing recommendations between the 2 equations. Patients for whom there was a recommendation discrepancy were found to have higher median SCr than patients with similar dosing recommendations between the 2 equations ( 107.5 versus $89 \mu \mathrm{mol} / \mathrm{L} ; p=0.035$ ).

Patients receiving DOAC therapy were discharged from hospital by family practice physicians $(n=56$ [41\%]), surgeons $(n=22[16 \%])$, cardiologists $(n=19[14 \%])$, internists $(n=15[11 \%])$, medical residents/students $(n=8[6 \%])$, respirologists $(\mathrm{n}=6[4 \%])$, nephrologists $(n=4[3 \%])$, neurologists $(n=3[2 \%])$, critical care intensivists $(n=2[1 \%])$, and a critical care associate $(n=1[1 \%])$. Statistical analyses were performed for the top 3 physician groups, with the remaining physicians categorized as "other". There were no significant differences by physician specialty in appropriateness of dosing on the basis of the CG-ABW equation $(p=0.85)$. The percentage of physicians in each specialty who prescribed an appropriate discharge dose ranged from 68\% to 82\% (Table 4).

\section{DISCUSSION}

The DOACs are high-risk medications, and their respective Canadian product monographs ${ }^{8-10}$ provide dosing recommendations to help ensure safe and effective use. The results of this study show that 1 in every 4 patients with atrial fibrillation was receiving an inappropriate dose of a DOAC at discharge, based on estimation of renal function using the CG-ABW equation.

For most of the patients receiving an inappropriate dose at discharge, the prescribed dose was subtherapeutic (15\% of all patients). A similar finding was reported in a study of

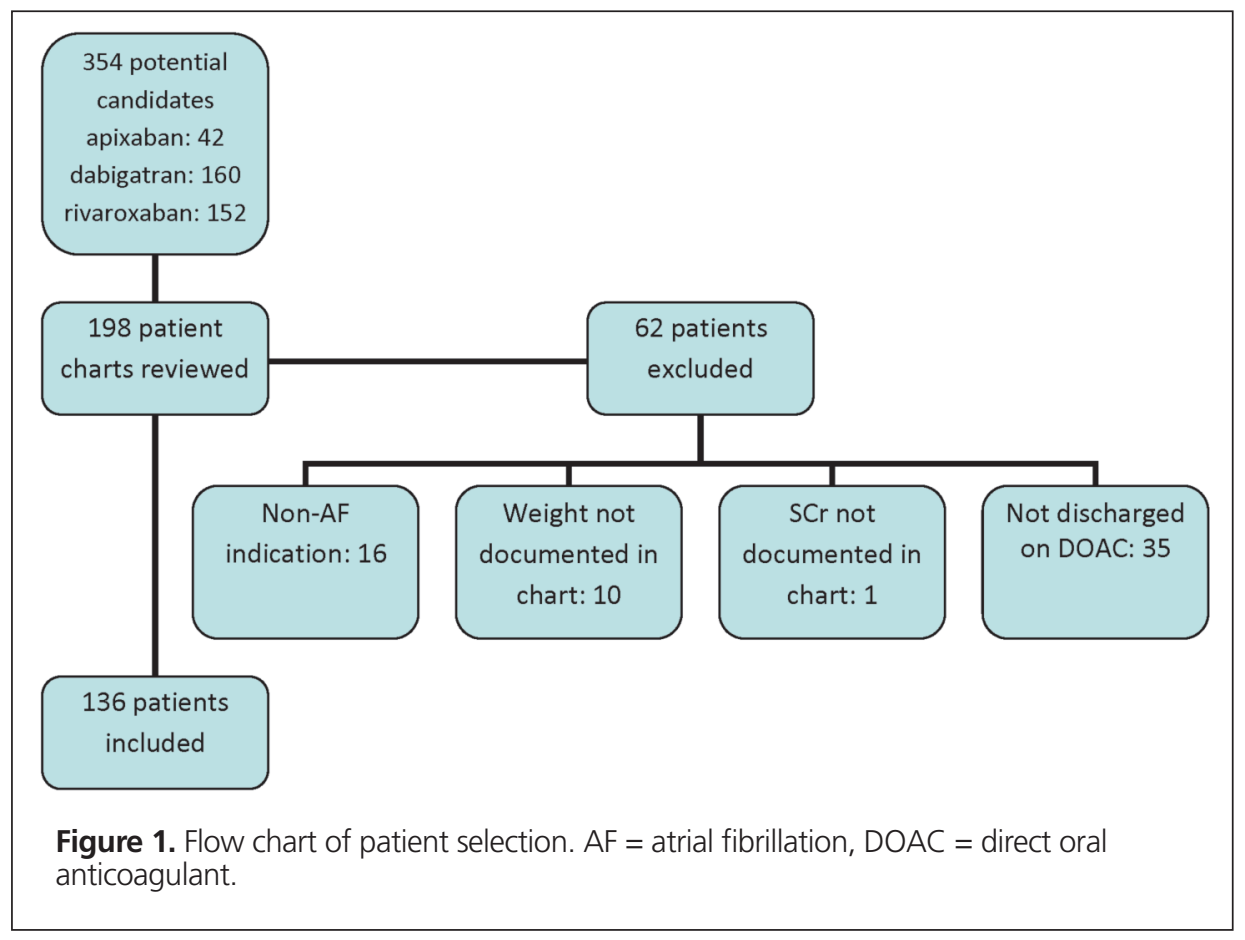


This single copy is for your personal, non-commercial use only.

For permission to reprint multiple copies or to order presentation-ready copies for distribution, contact CJHP at cjhpedit@cshp.ca

Table 1. Characteristics of Patients Included in a Retrospective Analysis of Direct Oral Anticoagulant Therapy in Older Adults

\begin{tabular}{|c|c|c|c|c|c|c|c|c|}
\hline \multirow[b]{2}{*}{ Characteristic } & \multicolumn{2}{|c|}{ Apixaban } & \multicolumn{2}{|c|}{ Dabigatran } & \multicolumn{3}{|c|}{ Rivaroxaban } & \multirow[b]{2}{*}{ Combined } \\
\hline & $\begin{array}{l}5-\mathrm{mg} \\
\text { Dose }\end{array}$ & $\begin{array}{c}\text { 2.5-mg } \\
\text { Dose }\end{array}$ & $\begin{array}{l}\text { 150-mg } \\
\text { Dose }\end{array}$ & $\begin{array}{l}\text { 110-mg } \\
\text { Dose }\end{array}$ & $\begin{array}{l}\text { 20-mg } \\
\text { Dose }\end{array}$ & $\begin{array}{l}\text { 15-mg } \\
\text { Dose }\end{array}$ & $\begin{array}{l}\text { 10-mg } \\
\text { Dose }\end{array}$ & \\
\hline No. of patients & 9 & 18 & 13 & 39 & 35 & 21 & 1 & 136 \\
\hline Sex, no. (\%) male & $3(33)$ & $5(28)$ & $10(77)$ & $16(41)$ & $23(66)$ & $12(57)$ & $0(0)$ & $69(51)$ \\
\hline Age (years) (mean \pm SD) & $76.4 \pm 8.0$ & $88.2 \pm 5.7$ & $72.4 \pm 3.2$ & $82.8 \pm 7.0$ & $75.2 \pm 7.4$ & $84.9 \pm 5.4$ & 90 & $80.5 \pm 8.3$ \\
\hline Weight $(\mathrm{kg})$ (median and IQR) & $\begin{array}{c}92 \\
(78.6-126.8)\end{array}$ & $\begin{array}{c}65 \\
(55.1-81.9)\end{array}$ & $\begin{array}{c}86.7 \\
(75.5-107.5)\end{array}$ & $\begin{array}{c}71.5 \\
(56.7-83.1)\end{array}$ & $\begin{array}{c}82.7 \\
(68.2-95)\end{array}$ & $\begin{array}{c}70 \\
(64.9-85.7)\end{array}$ & 55 & $\begin{array}{c}75 \\
(63.6-89.2)\end{array}$ \\
\hline $\begin{array}{l}\text { Serum creatinine ( } \mu \mathrm{mol} / \mathrm{L}) \\
\text { (median and IQR) }\end{array}$ & $\begin{array}{c}85 \\
(75.5-132.5)\end{array}$ & $\begin{array}{c}99 \\
(82.5-127.5)\end{array}$ & $\begin{array}{c}98 \\
(81.5-121.5)\end{array}$ & $\begin{array}{c}89 \\
(73-110)\end{array}$ & $\begin{array}{c}87 \\
(77-99)\end{array}$ & $\begin{array}{c}103 \\
(90.5-116)\end{array}$ & 63 & $\begin{array}{c}90.5 \\
(78.25-111.50)\end{array}$ \\
\hline \multicolumn{9}{|l|}{$\begin{array}{l}\text { Creatinine clearance } \\
(\mathrm{mL} / \mathrm{min})(\text { mean } \pm \mathrm{SD})\end{array}$} \\
\hline By CG-ABW equation & $72.7 \pm 21.0$ & $37.0 \pm 9.4$ & $77.1 \pm 20.1$ & $52.0 \pm 19.1$ & $79.3 \pm 41.4$ & $47.0 \pm 15.3$ & 45 & $60.1 \pm 30$ \\
\hline By modified CG equation & $54 \pm 15.4$ & $41.7 \pm 9.9$ & $66.3 \pm 30.0$ & $52.5 \pm 13.0$ & $69.7 \pm 32.1$ & $45.7 \pm 10.1$ & 61 & $55.9 \pm 23.2$ \\
\hline
\end{tabular}

$\overline{C G}=$ Cockcroft-Gault, CG-ABW= Cockcroft-Gault based on actual body weight, IQR = interquartile range, $\mathrm{SD}=$ standard deviation.

Table 2. Assessment of Discharge Doses Based on Canadian Product Monograph Recommendations, Using the Cockcroft-Gault Equation with Actual Body Weight

Drug; No. (\%) of Patients

\begin{tabular}{|c|c|c|c|c|}
\hline \multirow{3}{*}{$\begin{array}{l}\text { Dose Category } \\
\text { Subtherapeutic }\end{array}$} & \multirow[b]{2}{*}{ Apixaban $^{10}$} & \multirow{3}{*}{$\begin{array}{c}\text { Dabigatran }^{9} \\
\text { None }\end{array}$} & \multirow[b]{2}{*}{ Rivaroxaban $^{8}$} & \multirow[b]{2}{*}{ Combined } \\
\hline & & & & \\
\hline & $10(37)$ & & $10(18)$ & $20 \quad(15)$ \\
\hline Appropriate & $14(52)$ & $48 \quad(92)$ & $40(70)$ & (75) \\
\hline Supratherapeutic & $3(11)$ & $4 \quad(8)$ & $7(12)$ & $(10)$ \\
\hline Lower dose recommended & $2 \quad(7)$ & 0 & $4 \quad(7)$ & (4) \\
\hline Use not recommended & $1 \quad(4)$ & $4 \quad(8)$ & $3 \quad(5)$ & (6) \\
\hline Total & $27(100)$ & $52(100)$ & $57(100)$ & $136(100)$ \\
\hline
\end{tabular}

Table 3. Dosing Recommendations Based on Canadian Product Monographs Using Modified CG Equation, Relative to CG-ABW Equation

Dose Category with Modified CG Equation, No. (\%) of Patients Relative to CG-ABW Equation

Subtherapeutic dose

$(n=136)$

Same dosing recommendation as with

$6 \quad(4)$

CG-ABW equation

$120(88)$

Supratherapeutic dose*

$10 \quad(7)$

Total

$136(100)$

CG = Cockcroft-Gault, CG-ABW = Cockcroft-Gault based on actual body weight.

* Of the patients who would have received a supratherapeutic dose with the modified CG equation, 5 (4\% of the entire sample) would have received a direct oral anticoagulant at discharge, even though use of such therapy would not be recommended because of renal insufficiency.

patterns of dabigatran use among patients enrolled in an atrial fibrillation registry, in which $10 \%(91 / 920)$ of patients with preserved renal function had subtherapeutic dosing; clinical outcomes were not reported. ${ }^{18}$ Currently, there are no data on clinical outcomes for patients with subtherapeutic dosing of a DOAC. Studies have shown that the risk of thromboembolism increases markedly for patients with atrial fibrillation who are receiving warfarin when the international normalized ratio (INR) is less than 1.8, which may result in death for more than
$50 \%$ of patients and significant disability in the majority of those who survive. ${ }^{16,19}$ In the clinical trials, ${ }^{12-14}$ the rates of thromboembolic events among patients receiving DOACs at therapeutic doses were similar to the rate among patients receiving warfarin. As such, an increase in the risk of thromboembolic events is possible at subtherapeutic doses. Data from atrial fibrillation registries may provide further insight into the clinical outcomes associated with inappropriate dosing of DOACs.

Supratherapeutic dosing of anticoagulants is also of concern because the risk of hemorrhagic complications increases in this situation. ${ }^{16}$ Overall, about 1 in every 10 patients in this study was at increased risk of bleeding because a supratherapeutic dose of DOAC had been prescribed: $8 \%$ of patients receiving dabigatran, $11 \%$ of patients receiving apixaban, and $12 \%$ of patients receiving rivaroxaban. A 2013 review of the literature identified several case reports of severe hemorrhagic complications that occurred with supratherapeutic dosing of dabigatran and rivaroxaban..$^{20}$ This outcome is similar to what has been observed with warfarin therapy, whereby the risk of bleeding increases significantly with INR values above 3.5. ${ }^{16}$ Patients with severe renal impairment are particularly vulnerable to adverse bleeding events, because renal insufficiency is an independent risk factor for bleeding. ${ }^{2}$ As well, accumulation 
This single copy is for your personal, non-commercial use only.

For permission to reprint multiple copies or to order presentation-ready copies for distribution, contact CJHP at cjhpedit@cshp.ca

\section{Table 4. Assessment of Discharge Doses Based on Canadian Drug Monograph Recommendations, ${ }^{8-10}$ Using the Cockcroft-Gault Equation with Actual Body Weight, by Physician Specialty}

\begin{tabular}{|c|c|c|c|c|c|}
\hline \multirow[b]{2}{*}{ Dose Category } & \multicolumn{5}{|c|}{ Specialty; No. (\%) of Patients } \\
\hline & Family Physician & Surgeon & Cardiologist & Other* & Combined \\
\hline Subtherapeutic & $11(20)$ & $2 \quad(9)$ & $3(16)$ & $4(10)$ & $20 \quad(15)$ \\
\hline Appropriate & $38(68)$ & $18 \quad(82)$ & $15 \quad(79)$ & 31 (79) & 102 \\
\hline Supratherapeutic & 7 (12) & $2 \quad(9)$ & $1 \quad(5)$ & 4 (10) & 14 (10) \\
\hline Total & $56(100)$ & $22(100)$ & $19(100)$ & $39(100)$ & $136(100)$ \\
\hline
\end{tabular}

*Other physicians were critical care intensivists, critical care associates, internists, nephrologists, neurologists, respirologists, and medical residents.

of DOACs can occur in this population, which may further increase the risk of hemorrhagic complications. ${ }^{8-10}$ In the current study, 8 of the patients with a supratherapeutic dose upon discharge ( $6 \%$ of the entire sample) had a prescription for a DOAC despite poor renal function (a situation in which use of this therapy is not recommended); for most of these patients, dabigatran or rivaroxaban was prescribed. Patients with $\mathrm{CrCl}$ less than $30 \mathrm{~mL} / \mathrm{min}$ who were receiving dabigatran or rivaroxaban and those with $\mathrm{CrCl}$ less than $25 \mathrm{~mL} / \mathrm{min}$ who were receiving apixaban were excluded from the landmark clinical trials of DOACs in atrial fibrillation; thus, the safety and efficacy of DOAC therapy cannot be predicted for this population.

The CG-ABW and modified CG equations resulted in good agreement overall in terms of dosing recommendations. However, even though the discrepancies in dosing recommendations between the 2 equations were not statistically significant in the current study, impacts on the patient may be clinically relevant. For example, when there were discrepancies between the 2 equations, the patients affected the most were more likely to have a higher SCr value. Consequently, the greatest disagreement between the 2 equations occurred for patients in whom DOAC use was not recommended because of renal impairment: of the 8 patients identified as having renal impairment with the CG-ABW equation, only $3(38 \%)$ were identified as having renal impairment when the modified CG equation was used. Therefore, when providing dosing recommendations for the DOACs, it is important to consider that the randomized controlled trials used the CG-ABW equation and that use of the modified CG equation could result in different recommended doses, especially for patients with higher $\mathrm{SCr}$, which may in turn affect patient outcomes. ${ }^{12-14}$

Most of the patients in this study were discharged under the care of family practice physicians, surgeons, or cardiologists, a finding consistent with at least one other study, which identified cardiologists and family practitioners as the primary prescribers of DOACs. ${ }^{21}$ The current results indicate no significant difference in appropriateness of dosing of DOACs among different specialties, although the study was not adequately powered to detect such a difference. However, a trend toward less appropriate prescribing by family medicine practitioners was identified when assessing the discharge doses based on the CG-ABW equation.

This study had several limitations. Given that it was a retrospective analysis and long-term follow-up data were not available, clinically important outcomes associated with the doses prescribed, such as thromboembolic or hemorrhagic events, could not be reported. Also, European guidelines provide dosing recommendations for apixaban and rivaroxaban in patients with $\mathrm{CrCl}$ as low as $15 \mathrm{~mL} / \mathrm{min}$, which may account for the use of these agents in some patients with renal insufficiency. ${ }^{22}$ Another limitation is that SCr values are affected by many factors and hence may be dynamic; values for this variable should be interpreted on the basis of trends rather than single measurements. The DOAC doses were assessed on the basis of a single SCr value, which may not be a true representation of a patient's renal function. However, the last $\mathrm{SCr}$ reported in the chart is part of the final assessment of renal function before discharge and should be considered during prescribing. Weight is another dynamic variable that may not be frequently updated in the chart; weight variation could affect dosing recommendations.

\section{CONCLUSION}

According to an assessment of renal function using the CG-ABW equation, as recommended in the Canadian product monographs, 1 out of every 4 patients in the study sample was receiving an inappropriate dose of DOAC at discharge. Although the modified CG equation showed good agreement overall with the CG-ABW equation in this retrospective analysis, use of the CG-ABW equation is preferable, given that the modified CG equation identified fewer than half of the patients in whom DOAC use was not recommended because of renal insufficiency.

\section{References}

1. Atrial fibrillation - be pulse aware. Ottawa $(\mathrm{ON})$ : Heart and Stroke Foundation; [modified 2014 Sep; cited 2015 June 3]. Available from: www.heartandstroke.com/site/c.ikIQLcMWJtE/b.5052135/k.2C86/Hea rt_disease_Atrial_fibrillation.htm

2. Verma A, Cairns JA, Mitchell LB, Macle L, Stiell IG, Gladstone D, et al.; CCS Atrial Fibrillation Guidelines Committee. 2014 focused update of the Canadian Cardiovascular Society guidelines for the management of atrial fibrillation. Can J Cardiol. 2014;30(10):1114-30. 
3. Skanes AC, Healey JS, Cairns JA, Dorian P, Gillis AM, McMurtry MS, et al; Canadian Cardiovascular Society Atrial Fibrillation Guidelines Committee. Focused 2012 update of the Canadian Cardiovascular Society atrial fibrillation guidelines: recommendations for stroke prevention and rate/rhythm control. Can J Cardiol. 2012;28(2):125-36.

4. Baber U, Howard VJ, Halperin JL, Soliman EZ, Zhang X, McClellan $\mathrm{W}$, et al. Association of chronic kidney disease with atrial fibrillation among adults in the United States: REasons for Geographic And Racial Differences in Stroke (REGARDS) study. Circ Arrhythm Electrophysiol. 2011;4(1):26-32.

5. Fox KA, Piccini JP, Wojdyla D, Becker RC, Halperin JL, Nessel CC, et al. Prevention of stroke and systemic embolism with rivaroxaban compared with warfarin in patients with non-valvular atrial fibrillation and moderate renal impairment. Eur Heart J. 2011;32(19):2387-94.

6. Hijazi Z, Hohnloser SH, Oldgren J, Andersson U, Connolly SJ, Eikelboom JW, et al. Efficacy and safety of dabigatran compared with warfarin in relation to baseline renal function in patients with atrial fibrillation: a RE-LY (Randomized Evaluation of Long-term Anticoagulation Therapy) trial analysis. Circulation. 2014;129(9):961-70.

7. Sardar P, Chatterjee S, Herzog E, Nairooz R, Mukherjee D, Halperin JL. Novel oral anticoagulants in patients with renal insufficiency: a metaanalysis of randomized trials. Can J Cardiol. 2014;30(8):888-97.

8. Rivaroxaban. In: eTherapeutics [database on Internet]. Bayer; [updated 2015; cited 2015 June 3]. Available from: https://www.etherapeutics.ca/search. Subscription required to access content.

9. Dabigatran etexilate. In: eTherapeutics [database on Internet]. Boehringer Ingelheim; [updated 2015; cited 2015 June 3]. Available from: https://www.e-therapeutics.ca/search. Subscription required to access content.

10. Apixaban. In: eTherapeutics [database on Internet]. Bristol-Myers Squibb-Pfizer; [updated 2015; cited 2015 June 3]. Available from: https://www.e-therapeutics.ca/search. Subscription required to access content.

11. Esitmating glomerular filtration rate: the CKD-EPI equation. Bethesda (MD): National Institute of Diabetes and Digestive and Kidney Diseases; [updated 2014; cited 2015 June 3]. Available from: http://nkdep.nih.gov/ lab-evaluation/gfr/estimating.shtml\#the-ckd-epi-equation

12. Connolly SJ, Ezekowitz MD, Yusuf S, Eikelboom J, Oldgren J, Parekh A, et al.; RE-LY Steering Committee and Investigators. Dabigatran versus warfarin in patients with atrial fibrillation. $N$ Engl J Med. 2009; 361(12):1139-51

13. Granger CB, Alexander JH, McMurray JJV, Lopes RD, Hylek EM, Hanna M, et al.; ARISTOTLE Committee and Investigators. Apixaban versus warfarin in patients with atrial fibrillation. $N$ Engl J Med. 2011; 365(11):981-92.

14. Patel MR, Mahaffey KW, Garg J, Pan G, Singer DE, Hacke W, et al.; ROCKET AF Investigators. Rivaroxaban versus warfarin in nonvalvular atrial fibrillation. N Engl J Med. 2011;365(10):883-91.

15. Davis GA, Chandler MH. Comparison of creatinine clearance estimation methods in patients with trauma. Am J Health Syst Pharm. 1996; 53(9):1028-32.

16. Singer DE, Chang Y, Fang MC, Borowsky LH, Pomernacki NK, Udaltsova N, et al. Should patient characteristics influence target anticoagulation intensity for stroke prevention in nonvalvular atrial fibrillation? The ATRIA Study. Circ Cardiovasc Qual Outcomes. 2009; 2(4):297-304.
17. Chin PKL, Vella-Brincat JW, Walker SL, Barclay ML, Begg EJ. Dosing of dabigatran etexilate in relation to renal function and drug interactions at a tertiary hospital. Intern Med J. 2013;43(7):778-83.

18. Steinberg BA, Holmes DN, Piccini JP, Ansell J, Chang P, Fonarow GC, et al.; Outcomes Registry for Better Informed Treatment of Atrial Fibrillation (ORBIT-AF) Investigators and Patients. Early adoption of dabigatran and its dosing in US patients with atrial fibrillation: results from the Outcomes Registry for Better Informed Treatment of Atrial Fibrillation. J Am Heart Assoc. 2013;2(6):e000535.

19. Lin HJ, Wolf PA, Kelly-Hayes M, Beiser AS, Kase CS, Benjamin EJ, et al. Stroke severity in atrial fibrillation. The Framingham Study. Stroke. 1996;27(10):1760-4.

20. Pfeilschifter W, Luger S, Brunkhorst R, Lindhoff-Last E, Foerch C. The gap between trial data and clinical practice-an analysis of case reports on bleeding complications occurring under dabigatran and rivaroxaban anticoagulation. Cerebrovasc Dis. 2013;36(2):115-9.

21. Carley B, Griesbach S, Larson T, Krueger K. Assessment of dabigatran utilization and prescribing patterns for atrial fibrillation in a physician group practice setting. Am J Cardiol. 2014;113(4):650-4.

22. Heidbuchel H, Verhamme P, Alings M, Antz M, Hacke W, Oldgren J, et al. European Heart Rhythm Association practical guide on the use of new oral anticoagulants in patients with non-valvular atrial fibrillation. Europace. 2013;15(5):625-51.

Melissa Kucey, BSP, ACPR, is a Staff Pharmacist with the Department of Pharmacy, Regina Qu'Appelle Health Region, Regina, Saskatchewan.

Jennifer Bolt, BSCPharm, ACPR, PharmD, is Manager of Research and Development with the Department of Pharmacy, Regina Qu'Appelle Health Region, Regina, Saskatchewan.

Lori Albers, BSP, ACPR, is a Clinical Coordinator with the Department of Pharmacy, Regina Qu'Appelle Health Region, Regina, Saskatchewan.

Ali Bell, MA, MSc, is a Research Scientist providing research and performance support, Regina Qu'Appelle Health Region, Regina, Saskatchewan.

Nkem Iroh, PharmD, BCPS, is a Staff Pharmacist with the Department of Pharmacy, Regina Qu'Appelle Health Region, Regina, Saskatchewan.

Julie Toppings, BSP, ACPR, is a Staff Pharmacist with the Department of Pharmacy, Regina Qu'Appelle Health Region, Regina, Saskatchewan.

Competing interests: Jennifer Bolt has received speaker's honoraria from Boehringer Ingelheim for work unrelated to this study. No other competing interests were declared.

\section{Address correspondence to:}

Melissa Kucey

Department of Pharmacy

Regina Qu'Appelle Health Region

1440 - 14th Avenue

Regina SK S4P OW5

e-mail: melissa.kucey@rqhealth.ca

Funding: None received. 